\title{
Impact of Preoperative Fibrinogen Concentration on Postoperative Outcome in Patients Who Received Dual Antiplatelet Therapy in Proximity to Off-Pump Coronary Bypass Surgery
}

\author{
Na Young Kim, MD; Jae-Kwang Shim, MD, PhD; Jong Wook Song, MD; \\ Eui-Kyung Kim, MD; Young-Lan Kwak, MD, PhD
}

\begin{abstract}
Background: Preoperative fibrinogen concentration is associated with increased blood loss at the lower end, and with hypercoagulability-related ischemic event at the higher end in cardiac patients. We evaluated the influence of preoperative fibrinogen concentration on blood loss and outcome in patients who received clopidogrel in proximity to off-pump coronary artery bypass surgery (OPCAB).

Methods and Results: Medical records of 538 patients who received clopidogrel within 5 days of OPCAB (April 2007 to March 2012) were retrospectively reviewed. Perioperative bleeding and composite of morbidity endpoints including myocardial infarction were compared in relation to the tertile distribution of the fibrinogen concentration. The amount of blood loss was significantly larger in the first tertile, whereas the incidence of composite of morbidity endpoints was significantly higher in the third tertile. In multivariate analysis for risk factors of perioperative blood loss, body mass index and duration of surgery were identified as independent risk factors but not the fibrinogen level. And hypertension and preoperative fibrinogen level were identified as independent risk factors about composite of morbidity. The third tertile was associated with a 2-fold increased risk of developing composite of morbidity endpoints.

Conclusions: In patients who received dual antiplatelet therapy in proximity to OPCAB, increased preoperative fibrinogen concentration could serve as a valuable predictor for composite of morbidity endpoints, whereas low fibrinogen concentration was not found to be a risk factor of bleeding. (Circ $J$ 2014; 78: 1661-1666)
\end{abstract}

Key Words: Antiplatelet therapy; Coronary artery bypass; Fibrinogen; Outcome

$\mathbf{F}$ ibrinogen plays an important role in coagulation and also acts as an acute phase reactant in inflammatory state.,2 In cardiac surgical patients, preoperative fibrinogen concentration has been shown to be a predictor of increased blood loss and transfusion requirement.,2,3 Of note, elevated preprocedural fibrinogen level was reported to be a risk factor of thromboembolic complications following percutaneous coronary interventions. ${ }^{4,5}$ However, evidence regarding the clinical significance of elevated fibrinogen level in cardiac surgery is lacking.

\section{Editorial p1571}

Dual antiplatelet therapy (DAT) consisting of aspirin and clopidogrel is essential for patients with coronary artery disease (CAD); however, the accompanied risk of bleeding mandates discontinuation of clopidogrel 5-7 days prior to surgery requiring cardiopulmonary bypass (CPB). ${ }^{6}$ Nevertheless, trading-off increased bleeding risk for maximizing ischemic benefit by continuing clopidogrel could potentially enhance postoperative outcome in patients requiring surgical revascularization. ${ }^{7,8}$ Continuation of DAT was proven to be safe in terms of bleeding in off-pump coronary artery bypass surgery (OPCAB) as it avoids CPB-induced coagulopathy. ${ }^{9,10}$ However, this may not be applicable to all patients undergoing OPCAB considering the role of fibrinogen on platelet activation and aggregation. Depending on the fibrinogen concentration, risk of bleeding posed by continued DAT may be augmented at the lower end. In contrast, the risk of hypercoagulability-related adverse events, such as myocardial infarction (MI) would be increased at the higher end, which would be detrimental to patients at risk of ischemic events. Still, the effect of preoperative fibrinogen con-

Received February 9, 2014; revised manuscript received March 7, 2014; accepted March 19, 2014; released online April 16, 2014 Time for primary review: 24 days

Department of Anesthesiology and Pain Medicine (N.Y.K., J.-K.S., J.W.S., E.-K.K., Y.-L.K.), Anesthesia and Pain Research Institute (J.-K.S., J.W.S., Y.-L.K.), Severance Biomedical Science Institute (Y.-L.K.), Yonsei University College of Medicine, Seoul, Korea

Mailing address: Young-Lan Kwak, MD, PhD, Department of Anesthesiology and Pain Medicine, Yonsei University College of Medicine, 50 Yonsei-ro, Seodaemun-gu, Seoul 120-752, Republic of Korea. E-mail: ylkwak@yuhs.ac

ISSN-1346-9843 doi:10.1253/circj.CJ-14-0161

All rights are reserved to the Japanese Circulation Society. For permissions, please e-mail: cj@j-circ.or.jp 


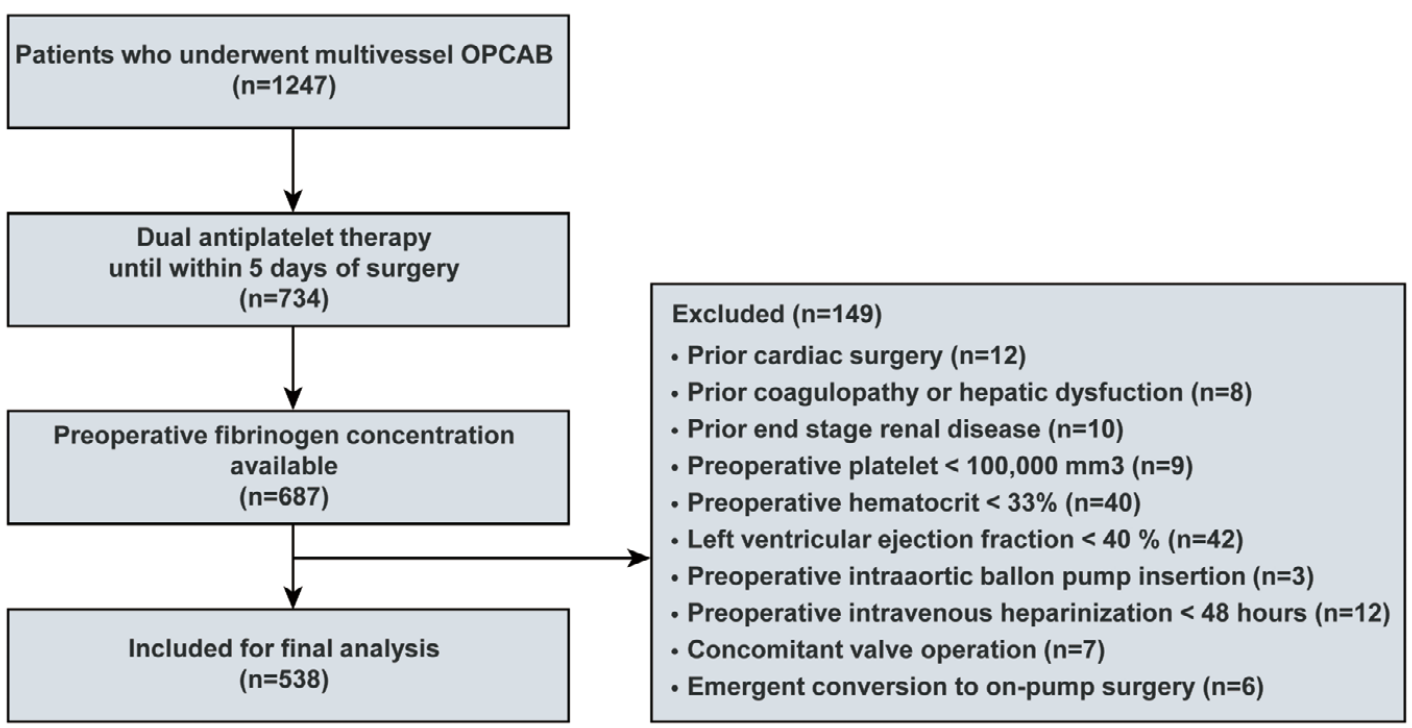

Figure. Flow chart demonstrating patient enrolment. OPCAB, off-pump coronary bypass surgery.

centration on bleeding and outcome in patients with recent DAT exposure before OPCAB has not been investigated heretofore.

In this retrospective review, we aimed to investigate the influence of preoperative fibrinogen concentration on perioperative blood loss and outcome in patients who continued aspirin and clopidogrel until within 5 days of OPCAB.

\section{Methods}

\section{Patients}

The current study was a retrospective review of data collected of a cohort of patients underwent multivessel OPCAB from April 2007 to March 2012. After the Institutional Review Board of Severance Hospital approval was obtained, prospectively entered electronic medical records of 538 patients who received aspirin and clopidogrel until within 5 days of OPCAB were reviewed. The need to obtain written informed consent from the patients was waived by the Institutional Review Board. Full-time researcher blinded to the details of the study adjudicated the data. Patients with following conditions were excluded: emergency or prior cardiac operation, coagulopathy or hepatic dysfunction, endstage renal disease, platelet count $<100,000 / \mathrm{mm}^{3}$, hematocrit (Hct) $<33 \%$, left ventricular ejection fraction (LVEF) $<40 \%$, preoperative intraaortic balloon pump insertion, preoperative intravenous heparinization $<48 \mathrm{~h}$, concomitant valve operation, emergency conversion to on-pump surgery. A flow chart of patient enrolment from 1,247 patients scheduled for elective OPCAB during study period is shown in the Figure.

\section{Clinical Management}

To all patients, standardized anesthetic and surgical management were provided. Anesthetic monitoring included a pulmonary artery catheter and transesophageal echocardiography. Anesthesia was induced with midazolam and sufentanil, and maintained with sufentanil and sevoflurane. All surgeries were performed by 2 surgeons through a median sternotomy. During mechanical heart displacement and grafting, norepinephrine was administered to maintain mean arterial blood pressure between 70 and $80 \mathrm{mmHg}$. Milrinone was administered to patients with mixed venous oxygen saturation $(\mathrm{SvO} 2)<60 \%$ persisting for $\geq 10 \mathrm{~min}$ and/or newly developed mitral regurgitation (MR) $\geq$ grade 3 with concomitant increase in mean pulmonary arterial pressure $\geq 30 \mathrm{mmHg}$.

During grafting, $100 \mathrm{IU} / \mathrm{kg}$ of heparin was administered to achieve a target activated clotting time $>250$ s. After completion of grafting, protamine sulfate $(0.5 \mathrm{mg} / 150 \mathrm{IU}$ of heparin) was administered. After the operation, patients were transferred to the intensive care unit (ICU), and treated according to a standardized protocol for postoperative care. Oral clopidogrel $(75 \mathrm{mg})$ and aspirin $(100 \mathrm{mg})$ were started from $24 \mathrm{~h}$ after the operation.

In all cases, salvaged blood from a cell salvage device was re-infused into the patient before the end of surgery, while chest tube drained-blood postoperatively was not re-infused. Packed red blood cell ( $\mathrm{pRBC}$ ) transfusion was performed when Hct $<25 \%$. When bleeding exceeded $>200 \mathrm{ml} / \mathrm{h}$ for 2 consecutive hours after the operation, fresh frozen plasma and/or platelet concentrates were transfused, in case of international normalized ratio $>1.5$ and platelet count $<50,000 / \mathrm{mm}^{3}$. Reoperation was performed when postoperative bleeding exceeded $200 \mathrm{ml} / \mathrm{h}$ for $\geq 6 \mathrm{~h}$ or $\geq 400 \mathrm{ml}$ for the first $1 \mathrm{~h}$. Final decisions for transfusion and reoperation were made at the discretion of the attending anesthesiologist and cardiac surgeon in the ICU.

\section{Data Collection}

Although data were recorded in retrospect using the electronic medical charts, all variables were prospectively assessed and recorded at predetermined time according to the institutional OPCAB protocol.

The assessed preoperative data were as follows: demographic data, preexisting conditions such as diabetes mellitus, hypertension, cerebrovascular accident, chronic lung disease, chronic kidney disease (CKD), unstable angina, and recent MI (within 1 month). New York Heart Association functional classifica- 
Table 1. Patients' Characteristics in Relation to Tertile Distribution of Preoperative Fibrinogen Concentration

Preoperative fibrinogen concentration $(\mathrm{mg} / \mathrm{dl})$

\begin{tabular}{|c|c|c|c|c|}
\hline & \multicolumn{3}{|c|}{ Preoperative fibrinogen concentration (mg/dl) } & \multirow[b]{2}{*}{$P$ value } \\
\hline & First tertile $(n=181)$ & Second tertile $(n=178)$ & Third tertile $(n=179)$ & \\
\hline & $96-305$ & $306-369$ & $370-854$ & \\
\hline Age, years & $64 \pm 9$ & $64 \pm 9$ & $66 \pm 8$ & 0.031 \\
\hline Female sex & $38(21)$ & $51(29)$ & $57(32)$ & 0.059 \\
\hline Body mass index, $\mathrm{kg} / \mathrm{m}^{2}$ & $24.7 \pm 3.0$ & $25.0 \pm 3.5$ & $24.3 \pm 3.1$ & 0.096 \\
\hline Hypertension & $115(64)$ & $133(75)$ & $118(66)$ & 0.058 \\
\hline Diabetes mellitus & $68(38)$ & $72(40)$ & $84(47)$ & 0.183 \\
\hline Prior cerebrovascular accident & $17(9)$ & $21(12)$ & $19(11)$ & 0.760 \\
\hline COPD & $1(1)$ & $2(1)$ & $4(2)$ & 0.359 \\
\hline Chronic kidney disease & $9(5)$ & $14(8)$ & $26(16)$ & 0.005 \\
\hline Unstable angina & $10(6)$ & $10(6)$ & $5(3)$ & 0.353 \\
\hline MI within 1 month & $42(23)$ & $51(29)$ & $73(41)$ & 0.001 \\
\hline NYHA functional classification $\geq$ III & $10(6)$ & $16(9)$ & $32(18)$ & $<0.001$ \\
\hline MR > grade 2 & $3(2)$ & $7(4)$ & $11(6)$ & 0.084 \\
\hline LVEF, \% & $59 \pm 12$ & $58 \pm 14$ & $54 \pm 15$ & 0.008 \\
\hline Hematocrit, \% & $39 \pm 4$ & $38 \pm 7$ & $36 \pm 6$ & $<0.001$ \\
\hline Platelet count, $10^{3} / \mu \mathrm{l}$ & $226 \pm 56$ & $239 \pm 60$ & $261 \pm 87$ & $<0.001$ \\
\hline \multicolumn{5}{|l|}{ Preoperative medication } \\
\hline$\beta$-blockers & $130(72)$ & $118(66)$ & $109(61)$ & 0.09 \\
\hline Renin-angiotensin system blockers & $104(58)$ & $109(61)$ & $113(63)$ & 0.533 \\
\hline Calcium-channel blockers & $88(49)$ & $89(50)$ & $82(46)$ & 0.722 \\
\hline Statins & $134(74)$ & $125(70)$ & $128(72)$ & 0.722 \\
\hline
\end{tabular}

Values are mean \pm SD or number of patients $(\%)$.

COPD, chronic obstructive pulmonary disease; LVEF, left ventricular ejection fraction; MI, myocardial infarction; MR, mitral regurgitation; NYHA, New York Heart Association.

\begin{tabular}{|c|c|c|c|c|}
\hline & \multicolumn{3}{|c|}{ Preoperative fibrinogen concentration (mg/dl) } & \multirow{3}{*}{$P$ value } \\
\hline & First tertile $(n=181)$ & Second tertile $(n=178)$ & Third tertile $(n=179)$ & \\
\hline & $96-305$ & $306-369$ & $370-854$ & \\
\hline No. of grafts & $3.2 \pm 0.7$ & $3.2 \pm 0.8$ & $3.3 \pm 0.8$ & 0.473 \\
\hline Duration of surgery, min & $239 \pm 46$ & $233 \pm 42$ & $232 \pm 46$ & 0.286 \\
\hline Perioperative blood loss, $\mathrm{ml}$ & $1,134 \pm 401$ & $1,067 \pm 472$ & $1,005 \pm 380$ & 0.014 \\
\hline Perioperative $\mathrm{pRBC}$ transfusion, units & $0(0-9)$ & $0(0-15)$ & $0(0-6)$ & 0.002 \\
\hline Perioperative FFP transfusion, units & $0(0-7)$ & $0(0-16)$ & $0(0-6)$ & 0.093 \\
\hline Perioperative platelet transfusion, units & $0(0-24)$ & $0(0-6)$ & $0(0-12)$ & 0.218 \\
\hline Postoperative MI & $10(6)$ & $17(10)$ & $25(14)$ & 0.025 \\
\hline STS morbidity endpoints & $20(11)$ & $24(14)$ & $37(21)$ & 0.030 \\
\hline Permanent stroke & $0(0)$ & $2(1)$ & $1(1)$ & 0.360 \\
\hline Renal failure & $6(3)$ & $6(3)$ & $8(5)$ & 0.809 \\
\hline Deep sternal wound infection & $4(2)$ & $1(1)$ & $6(3)$ & 0.173 \\
\hline Mechanical ventilation $>24 \mathrm{~h}$ & $10(6)$ & $10(6)$ & $19(11)$ & 0.104 \\
\hline Reoperation & $1(1)$ & $4(2)$ & $1(1)$ & 0.215 \\
\hline Operative mortality & $1(1)$ & $2(1)$ & $0(0)$ & 0.362 \\
\hline Composite of morbidity endpoints & $25(14)$ & $37(21)$ & $53(30)$ & 0.001 \\
\hline Duration of ICU stay, days & $2 \pm 1$ & $3 \pm 2$ & $3 \pm 1$ & 0.023 \\
\hline Duration of hospitalization, days & $10 \pm 4$ & $10 \pm 6$ & $12 \pm 8$ & $<0.001$ \\
\hline
\end{tabular}

Values are mean $\pm \mathrm{SD}$, median (range) or number of patients (\%).

Composite of morbidity endpoints, STS morbidity endpoints and postoperative myocardial infarction combined; FFP, fresh frozen plasma; ICU, intensive care unit; pRBC, packed red blood cell; STS, The Society of Thoracic Surgeons. Other abbreviations as in Table 1.

tion (NYHA), grade of MR, and LVEF were also assessed. Laboratory data including fibrinogen level, Hct level, and platelet count were recorded. Reference value of fibrinogen concentration is $200-400 \mathrm{mg} / \mathrm{dl}$. Assessed intraoperative data were du- ration of surgery, and number of grafts performed. Transfusion requirement and the amount of blood loss (which was recorded as the amount of re-infused salvaged blood by the cell salvage device) were also assessed. Assessed postoperative data were 


\begin{tabular}{|c|c|c|}
\hline \multirow{2}{*}{ Variables } & \multicolumn{2}{|c|}{ Multivariate analysis } \\
\hline & OR $(95 \% \mathrm{Cl})$ & $P$ value \\
\hline Age, years & $1.024(0.994-1.055)$ & 0.111 \\
\hline Female sex & $1.455(0.879-2.407)$ & 0.144 \\
\hline Body mass index, $\mathrm{kg} / \mathrm{m}^{2}$ & $0.772(0.706-0.844)$ & $<0.001$ \\
\hline Preoperative hematocrit, \% & $0.968(0.933-1.004)$ & 0.084 \\
\hline Duration of surgery, min & $1.009(1.004-1.014)$ & $<0.001$ \\
\hline
\end{tabular}

$\mathrm{Cl}$, confidence interval; OR, odds ratio.

as follows: amount of postoperative blood (amount of chest tube drainage for $24 \mathrm{~h}$ after surgery) and transfusion requirement of pRBC, fresh frozen plasma and platelet concentrates during $24 \mathrm{~h}$ after surgery.

From the definition of Society of Thoracic Surgeons (STS) Risk Model, ${ }^{11}$ major morbidity endpoints were permanent stroke, renal failure, prolonged ventilator care $>24 \mathrm{~h}$, deep sternal wound infection, 30-day operative mortality, and reoperation. Postoperative renal failure pertained to $(1)>2.0 \mathrm{mg} / \mathrm{dl}$ increase in serum creatinine, (2) $\geq 50 \%$ creatinine increase compared with the baseline value before surgery, and (3) new demands for dialysis. MI was defined as the occurrence of increase in troponin- $\mathrm{T}$ level $\geq 0.5 \mathrm{ng} / \mathrm{ml}$ (5-fold above the upper normal limit) and development of new pathologic $\mathrm{Q}$ wave or new left bundle branch block on ECG. ${ }^{12}$ The lengths of ICU and hospital stay were also assessed.

\section{Endpoints}

Perioperative blood loss and composite of morbidity endpoints (STS morbidity endpoints and postoperative MI combined) were compared in relation to the tertile distribution of the preoperative fibrinogen concentrations. Evaluation of risk factors for significant perioperative blood loss ( $\geq 30 \%$ of the estimated blood volume [male: $75 \mathrm{ml} / \mathrm{kg}$, female: $65 \mathrm{ml} / \mathrm{kg}$ ]) and composite of morbidity endpoints were performed.

\section{Statistical Analysis}

SPSS 18.0 (SPSS Inc, Chicago, IL, USA) was used to perform statistical analysis. Data are shown as mean $\pm \mathrm{SD}$, median (range) or number of patients (percentage). Comparisons between the tertiles of the preoperative fibrinogen were analyzed by 1-way analysis of variance, Kruskal-Wallis test, $\chi^{2}$ test or Fisher's exact test where appropriate. $\mathrm{P}$ values of multiple comparisons were adjusted by Bonferroni correction. Logistic regression analysis was used to identify predictors of perioperative blood loss greater than $30 \%$ of the estimated blood volume or composite of morbidity endpoints. Variables were chosen on the basis of literature review. Firstly, each of the variables was analyzed by univariate logistic regression. Variables with $\mathrm{P}<0.1$ on univariate analysis were included in multivariate logistic regression analysis to identify independent predictors. Odds ratios and associated $95 \%$ confidence interval (CI) were calculated. $\mathrm{P}<0.05$ was regarded as statistically significant.

\section{Results}

A total of 538 patients were enrolled. Their characteristics and the range of preoperative fibrinogen levels according to the tertile distribution are shown in Table 1. Age, CKD, recent MI, NYHA class $\geq$ III, LVEF, Hct level and platelet count were significantly different among the tertiles. Patients in the third

\begin{tabular}{lcc} 
Table 4. Predictors of Composite of Morbidity Endpoints \\
\cline { 2 - 3 } \multicolumn{1}{c}{ Variables } & \multicolumn{2}{c}{ Multivariate analysis } \\
\cline { 2 - 3 } Age, years & OR (95\% Cl) & P value \\
Hypertension & $1.017(0.989-1.046)$ & 0.235 \\
Chronic kidney disease & $1.733(1.031-2.914)$ & 0.038 \\
MI within 1 month & $0.129(0.536-2.377)$ & 0.749 \\
NYHA functional & $1.021(0.505-1.693)$ & 0.977 \\
classification $\geq$ III & & 0.955 \\
MR >grade 2 & $2.567(0.995-6.621)$ & 0.051 \\
LVEF, \% & $0.988(0.971-1.004)$ & 0.144 \\
Preoperative hematocrit, \% & $0.991(0.953-1.031)$ & 0.662 \\
Preoperative fibrinogen, mg/dl & $1.003(1.000-1.005)$ & 0.018 \\
\hline
\end{tabular}

MR, mitral regurgitation. Other abbreviations as in Tables 1,2.

tertile were older than those in the second tertile. More patients in the third tertile had CKD and were in NYHA class $\geq$ III than those in the first tertile. More patients in the third tertile had had a recent MI than those in the first and second tertiles. The LVEF was lower in the third tertile than in the first tertile, and the Hct level was lower and platelet counts were higher in the third tertile than in other tertiles.

Operative characteristics and outcome variables are listed in Table 2. The amount of perioperative blood loss was larger in the first tertile than in the third tertile, while the pRBC transfusion requirement was higher in the third tertile compared with other tertiles. Both the incidence of postoperative MI and the composite of morbidity endpoints (STS morbidity endpoints and postoperative MI) were significantly higher in the third tertile than in the first tertile. Also, the length of hospital stay was significantly longer in the third tertile than in the first tertile.

In the univariate analysis for risk factors of significant perioperative blood loss (111 patients), age, female sex, body mass index, preoperative Hct level, and duration of surgery were identified as risk factors. After multivariate analysis of these variables, body mass index and duration of surgery remained as independent risk factors (Table 3).

In the univariate analysis for risk factors of composite morbidity endpoints, age, hypertension, CKD, recent MI, NYHA class $\geq$ III, MR $\geq$ grade 2 , LVEF, and the preoperative Hct and fibrinogen levels were identified as risk factors. After multivariate analysis of these risk factors, hypertension and the preoperative fibrinogen level remained as independent risk factors (Table 4). When the tertile distribution of fibrinogen was entered into the multivariate analysis instead of fibrinogen as a continuous variable, hypertension and the third tertile remained as independent risk factors. The third tertile showed a 2-fold increased risk of developing the composite of morbidity endpoints compared with the first tertile (95\% CI 1.162-3.597, $\mathrm{P}=0.013)$.

\section{Discussion}

In this retrospective study addressing the effect of the preoperative fibrinogen level on bleeding and outcome in patients who received DAT until within 5 days prior to $\mathrm{OPCAB}$, an elevated preoperative fibrinogen level was found to be an independent risk factor of a composite of morbidity endpoints including MI, and was associated with prolonged hospital stay. In contrast, a low fibrinogen level was not an independent risk factor of increased perioperative blood loss.

Fibrinogen is one of the coagulation factors to act and be 
consumed firstly during the process of bleeding and hemostasis. It stabilizes blood clots by combining to coagulation factor $\mathrm{XIII}$ and plays important roles in platelet activation as well as agglutination by combining to platelet glycoprotein IIb/IIIa receptors. ${ }^{1,13}$ Accordingly, several studies have depicted the prognostic significance of the preoperative fibrinogen level on blood loss and transfusion requirement in cardiac surgery. ${ }^{2,3}$ Of interest, fibrinogen's major influence on thrombus formation could also incur thrombus-related adverse cardiovascular events. ${ }^{13}$ Indeed, an elevated fibrinogen level has been shown to be a significant risk factor of cardiovascular events in cardiac patients. ${ }^{14,15}$

Because of its invaluable influence on preventing recurrent ischemic attacks, dual or even triple antiplatelet therapy has become the cornerstone of treatment in patients with CAD. ${ }^{16,17}$ Despite concerns for consequent risk of hemorrhagic complications, increasing evidence favors a certain level of platelet inhibition at the time of surgery to maximize the ischemic benefit and improve the postoperative outcome. ${ }^{7,8}$ In that context, OPCAB is proposed to be a safe surgical technique without increased risk of bleeding in patients requiring continued DAT. ${ }^{9,18}$ Nonetheless, concerns about procoagulant activity after OPCAB is also an important issue, as OPCAB may increase the risk of venous thrombosis and threaten the patency of coronary anastomosis, ${ }^{19,20}$ which would be detrimental in patients at highrisk of ischemic events. Thus, extremes of preoperative fibrinogen level would exert a significant influence on blood loss and outcome in patients undergoing OPCAB. However, the evidence in that regard has been lacking heretofore, especially in patients who received DAT in proximity to OPCAB.

As our results indicate, patients in the first tertile of fibrinogen level were associated with larger amounts of blood loss. However, the relation between low fibrinogen level and perioperative blood loss was lost after multivariate analysis. Higher perioperative $\mathrm{pRBC}$ transfusion requirement in the third tertile compared with the first and second tertiles may likely be attributable to the lower preoperative Hct level in the third tertile. These results contradict the results of previous studies that demonstrated close relationships between preoperative fibrinogen level and postoperative bleeding. ${ }^{3}$ Yet it is difficult to make direct comparisons between the results of the current study with those of previous studies because antiplatelet agents were stopped at least 5 days before operation in all of the previous studies and surgeries were mostly performed under CPB. Plausible explanations for the discrepancy are as follows. Compared with on-pump coronary revascularization, the postoperative fibrinogen level is significantly less decreased in $\mathrm{OPCAB},{ }^{21}$ whereas a direct relationship exists between the preoperative and postoperative fibrinogen levels. ${ }^{22}$ Thus, the postoperative fibrinogen levels of the patients in the current study could be speculated to be higher than the aforementioned critical value, even in the patients of the first tertile, although we did not have available data in that regard. Furthermore, a minor decrease in the platelet count in OPCAB might also have contributed to the observed result because the role of fibrinogen in coagulation becomes critical under thrombocytopenia as in the post-CPB period. ${ }^{23}$

Elevated fibrinogen levels are regarded as a significant risk factor for cardiovascular events ${ }^{14,24}$ and a close relationship between the extent of coronary atherosclerosis and fibrinogen level has been reported. ${ }^{25}$ The prognostic importance of an elevated fibrinogen level in acute coronary syndrome and restenosis after percutaneous coronary balloon angioplasty, as well as stent insertion, has been described., ${ }^{4,5}, 26$ Although evidence is far less scarce in the surgical setting, hypercoagulability associated with elevated preoperative fibrinogen levels resulted in raised 30-day event rate including MI, stroke and mortality in patients undergoing on-pump coronary revascularization. ${ }^{27}$ In accordance with those studies, an elevated fibrinogen level was an independent risk factor of a composite of morbidity endpoints including postoperative MI in current study, resulting in prolonged hospital stay. Our results imply that the ischemic benefit provided by a certain level of platelet inhibition at the time of surgery could be mitigated by a high preoperative fibrinogen level representing a hypercoagulable and systemic inflammatory status of the patient. Possible mechanisms for the observed results are as follows. Glycoprotein IIb/IIIa receptor antagonists have been shown to mitigate both hemostatic and thrombotic capacity through impairment of fibrinogen-mediated platelet cross-linking in an in-vitro experiment. ${ }^{28}$ Inversely, the effect of antiplatelet agents could be antagonized through increasing fibrinogen levels. ${ }^{23,28}$ Furthermore, an elevated fibrinogen level $(>350 \mathrm{mg} / \mathrm{dl})$, together with elevated C-reactive protein $(>5 \mathrm{mg} / \mathrm{L})$ and white blood cell count, shows a significant correlation with high platelet reactivity even in patients under chronic clopidogrel treatment. ${ }^{29}$ Also, a high fibrinogen level was shown to be related to higher baseline adenosine diphosphate-induced platelet aggregation compared with the normal fibrinogen level. ${ }^{29}$

\section{Study Limitations}

Even though the patients' data were entered prospectively, this study is subject to limitations inherent to the retrospective design and thus, causality cannot be assumed. Another limitation is that the decision to continue DAT was at the discretion of the attending cardiologists and surgeon. Considering that the overall incidence of recent MI within 1 month before surgery in the study population was $31 \%$ and all patients received multivessel grafting, we can only speculate that the studied population was at risk of ischemic events in need of antiplatelet therapy. The strength of this study lies in it being one of the largest studies to evaluate the influence of preoperative fibrinogen level on patients' prognoses and the only study to observe the diverse effects of fibrinogen levels at both extremes in patients undergoing $\mathrm{OPCAB}$.

\section{Conclusions}

In patients who receive DAT in proximity to OPCAB, an elevated preoperative fibrinogen level can be an independent risk factor for a composite of morbidity endpoints including MI, resulting in prolonged hospital stay. As continuation of DAT would not ensure ischemic benefit in patients with an elevated fibrinogen level, it seems advisable to take this into account in surgical planning. Future studies looking to modify this risk factor are warranted to show any benefit of specific interventions.

\section{Acknowledgments}

None.

\section{Disclosures}

None.

\section{References}

1. Mosesson MW. Fibrinogen and fibrin structure and functions. $J$ Thromb Haemost 2005; 3: 1894-1904.

2. Ucar HI, Oc M, Tok M, Dogan OF, Oc B, Aydin A, et al. Preoperative fibrinogen levels as a predictor of postoperative bleeding after open heart surgery. Heart Surg Forum 2007; 10: E392-E396, doi:10.1532/ HSF98.20071065. 
3. Karlsson M, Ternstrom L, Hyllner M, Baghaei F, Nilsson S, Jeppsson A. Plasma fibrinogen level, bleeding, and transfusion after on-pump coronary artery bypass grafting surgery: A prospective observational study. Transfusion 2008; 48: 2152-2158.

4. Lupi A, Secco GG, Rognoni A, Rossi L, Lazzero M, Nardi F, et al. Plasma fibrinogen levels and restenosis after primary percutaneous coronary intervention. J Thromb Thrombolysis 2012; 33: 308-317.

5. Ang L, Thani KB, Ilapakurti M, Lee MS, Palakodeti V, Mahmud E. Elevated plasma fibrinogen rather than residual platelet reactivity after clopidogrel pre-treatment is associated with an increased ischemic risk during elective percutaneous coronary intervention. $J \mathrm{Am}$ Coll Cardiol 2013; 61: 23-34.

6. Anderson JL, Adams CD, Antman EM, Bridges CR, Califf RM, Casey $\mathrm{DE} \mathrm{Jr}$, et al. ACC/AHA 2007 guidelines for the management of patients with unstable angina/non-ST-Elevation myocardial infarction: A report of the American College of Cardiology/American Heart Association Task Force on Practice Guidelines (Writing Committee to Revise the 2002 Guidelines for the Management of Patients With Unstable Angina/Non-ST-Elevation Myocardial Infarction) developed in collaboration with the American College of Emergency Physicians, the Society for Cardiovascular Angiography and Interventions, and the Society of Thoracic Surgeons endorsed by the American Association of Cardiovascular and Pulmonary Rehabilitation and the Society for Academic Emergency Medicine. J Am Coll Cardiol 2007; 50: e1-e157, doi:10.1016/j.jacc.2007.02.013.

7. Ebrahimi R, Dyke C, Mehran R, Manoukian SV, Feit F, Cox DA, et al. Outcomes following pre-operative clopidogrel administration in patients with acute coronary syndromes undergoing coronary artery bypass surgery: The ACUITY (Acute Catheterization and Urgent Intervention Triage strategY) trial. J Am Coll Cardiol 2009; 53: 1965 1972.

8. Nijjer SS, Watson G, Athanasiou T, Malik IS. Safety of clopidogrel being continued until the time of coronary artery bypass grafting in patients with acute coronary syndrome: A meta-analysis of 34 studies. Eur Heart J 2011; 32: 2970-2988.

9. Shim JK, Choi YS, Oh YJ, Bang SO, Yoo KJ, Kwak YL. Effects of preoperative aspirin and clopidogrel therapy on perioperative blood loss and blood transfusion requirements in patients undergoing offpump coronary artery bypass graft surgery. J Thorac Cardiovasc Surg 2007; 134: 59-64.

10. Ahn SW, Shim JK, Youn YN, Song JW, Yang SY, Chung SC, et al. Effect of tranexamic acid on transfusion requirement in dual antiplatelet-treated anemic patients undergoing off-pump coronary artery bypass graft surgery. Circ J 2012; 76: 96-101.

11. Shroyer AL, Coombs LP, Peterson ED, Eiken MC, DeLong ER, Chen A, et al. The Society of Thoracic Surgeons: 30-day operative mortality and morbidity risk models. Ann Thorac Surg 2003; 75: 1856-1864; discussion 1864-1855.

12. Thygesen K, Alpert JS, White HD; Joint ESC/ACCF/AHA/WHF Task Force for the Redefinition of Myocardial Infarction, Jaffe AS, Apple FS, Galvani M, et al. Universal definition of myocardial infarction. Circulation 2007; 116: 2634-2653.

13. Fuss C, Palmaz JC, Sprague EA. Fibrinogen: Structure, function, and surface interactions. J Vasc Interv Radiol 2001; 12: 677-682.

14. Kannel WB, Wolf PA, Castelli WP, D'Agostino RB. Fibrinogen and risk of cardiovascular disease: The Framingham Study. JAMA 1987; 258: $1183-1186$.

15. Volzke H, Robinson DM, Kleine V, Hertwig S, Schwahn C, Grimm $\mathrm{R}$, et al. Preoperative plasma fibrinogen levels predict mortality after coronary artery bypass grafting. Thromb Haemost 2003; 89: 885891.

16. Nappi J, Talbert R. Dual antiplatelet therapy for prevention of recurrent ischemic events. Am J Health Syst Pharm 2002; 59: 1723-1735.

17. Fujita J. Report of the American Heart Association (AHA) Scientific Sessions 2012, Los Angeles. Circ J 2013; 77: 35-40.

18. Woo YJ, Grand T, Valettas N. Off-pump coronary artery bypass grafting attenuates postoperative bleeding associated with preoperative clopidogrel administration. Heart Surg Forum 2003; 6: 282-285.

19. Mariani MA, Gu YJ, Boonstra PW, Grandjean JG, van Oeveren W, Ebels T. Procoagulant activity after off-pump coronary operation: Is the current anticoagulation adequate? Ann Thorac Surg 1999; 67: $1370-1375$.

20. Parolari A, Mussoni L, Frigerio M, Naliato M, Alamanni F, Galanti $\mathrm{A}$, et al. Increased prothrombotic state lasting as long as one month after on-pump and off-pump coronary surgery. J Thorac Cardiovasc Surg 2005; 130: 303-308

21. Momeni M, Carlier C, Baele P, Watremez C, Van Dyck M, Matta A, et al. Fibrinogen concentration significantly decreases after on-pump versus off-pump coronary artery bypass surgery: A systematic pointof-care ROTEM analysis. J Cardiothorac Vasc Anesth 2013; 27: $5-11$.

22. Ternstrom L, Radulovic V, Karlsson M, Baghaei F, Hyllner M, Bylock A, et al. Plasma activity of individual coagulation factors, hemodilution and blood loss after cardiac surgery: A prospective observational study. Thromb Res 2010; 126: e128-e133, doi:10.1016/j. thromres.2010.05.028.

23. Velik-Salchner C, Haas T, Innerhofer P, Streif W, Nussbaumer W, Klingler A, et al. The effect of fibrinogen concentrate on thrombocytopenia. J Thromb Haemost 2007; 5: 1019-1025.

24. Wilhelmsen L, Svardsudd K, Korsan-Bengtsen K, Larsson B, Welin $\mathrm{L}$, Tibblin G. Fibrinogen as a risk factor for stroke and myocardial infarction. N Engl J Med 1984; 311: 501-505.

25. Handa K, Kono S, Saku K, Sasaki J, Kawano T, Sasaki Y, et al. Plasma fibrinogen levels as an independent indicator of severity of coronary atherosclerosis. Atherosclerosis 1989; 77: 209-213.

26. Otsuka M, Hayashi Y, Ueda H, Imazu M, Kohno N. Predictive value of preprocedural fibrinogen concerning coronary stenting. Atherosclerosis 2002; 164: 371-378.

27. Rafiq S, Johansson PI, Ostrowski SR, Stissing T, Steinbruchel DA. Hypercoagulability in patients undergoing coronary artery bypass grafting: Prevalence, patient characteristics and postoperative outcome. Eur J Cardiothorac Surg 2012; 41: 550-555.

28. Li YF, Spencer FA, Becker RC. Comparative efficacy of fibrinogen and platelet supplementation on the in vitro reversibility of competitive glycoprotein IIb/IIIa (alphaIIb/beta3) receptor-directed platelet inhibition. Am Heart J 2001; 142: 204-210.

29. Bernlochner I, Steinhubl S, Braun S, Morath T, Jaitner J, Stegherr J, et al. Association between inflammatory biomarkers and platelet aggregation in patients under chronic clopidogrel treatment. Thromb Haemost 2010; 104: 1193-1200. 